\title{
Comparison of cadmium and lead sorption by Phyllostachys pubescens biochar produced under a low-oxygen pyrolysis atmosphere
}

\author{
Chao Zhang, Baoqing Shan ${ }^{1}$, Wenzhong Tang ${ }^{*, 1}$, Yaoyao Zhu \\ State Key Laboratory of Environmental Aquatic Chemistry, Research Center for Eco-Environmental Sciences, Chinese Academy of Sciences, Beijing 100085, PR China \\ University of Chinese Academy of Science, Beijing 100049, PR China
}

\section{H I G H L I G H T S}

- Low oxygen atmosphere could improve sorption capacity of metals.

- The biochar had more favorable adsorption for $\mathrm{Pb}^{2+}$ than $\mathrm{Cd}^{2+}$.

- Precipitation with ash mechanisms dominated $\mathrm{Pb}^{2+}$ sorption on the biochars.

- Coordination with $\pi$ electron mechanisms dominated $\mathrm{Cd}^{2+}$ sorption.

\section{G R A P H I C A L A B S T R A C T}
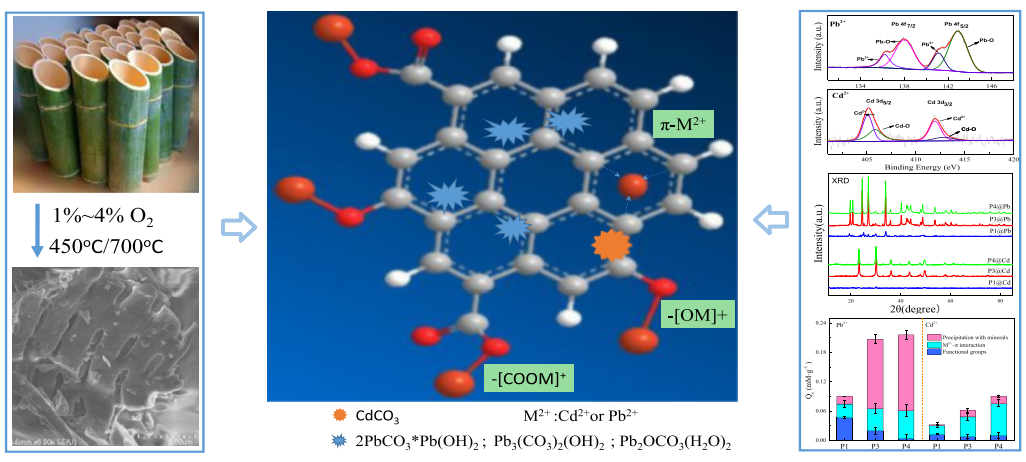

A B S T R A C T

Phyllostachys pubescens (PP) biochars produced under a low oxygen pyrolysis atmosphere (oxygen content $1-4 \%$ ) were prepared as sorbents for investigating the mechanisms of cadmium and lead sorption. A low-oxygen pyrolysis atmosphere increased biochar ash and specific surface area, promoting heavy metal precipitation and complexation. The maximum sorption capacity $\left(\mathrm{Q}_{\mathrm{m}}\right)$ of $\mathrm{Pb}^{2+}$ obtained from the Langmuir model was $67.4 \mathrm{mg} \cdot \mathrm{g}^{-1}$, while $\mathrm{Q}_{\mathrm{m}}$ of $\mathrm{Cd}^{2+}$ was $14.7 \mathrm{mg} \cdot \mathrm{g}^{-1}$. The contribution of each mechanism varied with increasing oxygen content at a low pyrolysis temperature. Mineral precipitation with $\mathrm{Pb}^{2+}$ was the predominant mechanism for $\mathrm{Pb}^{2+}$ removal and the contribution proportion significantly increased from $17.2 \%$ to $71.7 \%$ as pyrolysis oxygen atmosphere increased from $0 \%$ to $4 \%$. The results showed that cadmium sorption primarily involved coordination with $\pi$ electrons, at $54.1-82.6 \%$ of the total adsorption capacity. The PP biochar shows potential for application in removing heavy metal contaminants, especially $\mathrm{Pb}^{2+}$.

(c) 2017 Elsevier Ltd. All rights reserved.

\section{Introduction}

Biochar has been successfully applied for soil remediation, carbon sequestration, climate change mitigation, and carbon farming

\footnotetext{
* Corresponding author at: Research Center for Eco-Environmental Sciences, Chinese Academy of Sciences, Beijing 100085, PR China.

E-mail addresses: bqshan@rcees.ac.cn (B. Shan), wztang@rcees.ac.cn (W. Tang).

${ }^{1}$ B.Q. Shan and W.Z. Tang contributed equally to this paper.
}

(Ahmad et al., 2014; Bell and Worrall, 2011; Mohan et al., 2014). In recent years, biochar has been widely applied to water and wastewater for the removal of organic and inorganic contaminants, especially for the effective removal of heavy metals, including lead $\left(\mathrm{Pb}^{2+}\right)$ and cadmium $\left(\mathrm{Cd}^{2+}\right)$ (Ding et al., 2016; Dong et al., 2014; Wang et al., 2015). Depending on the biochar type, heavy metals can be removed by different mechanisms: precipitation with minerals (e.g., phosphate and carbonate); surface complexation with oxygen-containing functional groups (e.g., phenolic, carboxyl, and 
hydroxyl groups); and coordination of heavy metals with $\pi$ electrons (e.g., $\mathrm{Pb}^{2+}-\pi$ and $\mathrm{Cd}^{2+}-\pi$ ) (Cui et al., 2016; Lu et al., 2012; Wang et al., 2015). Experiments have confirmed that the proposed mechanisms could be attributed to properties of the biochar, such as ash content, zeta potential, surface area, and other surface characteristics (Fang et al., 2014; Liu et al., 2015; Mohan et al., 2014). I Different biochar properties also influence the adsorption capacities for different heavy metals (Ding et al., 2016; Inyang et al., 2012; Xue et al., 2012). Examination of exact mechanisms for $\mathrm{Pb}^{2+}$ and $\mathrm{Cd}^{2+}$ sorption on biochars produced under different conditions is crucial. However, there are relatively few studies devoted to simultaneously providing qualitative and quantitative information regarding the relative contribution of the involved mechanisms and comparing sorption mechanisms for different heavy metals on biochars produced under different pyrolysis conditions.

Properties of biochars are not only strongly dependent on biomass feedstocks but also on production conditions (Enders et al., 2012; Luo et al., 2015). Many studies have attempted to explore the relationships between biochar properties and pyrolysis conditions, which include temperature (Dong et al., 2013; Zhang et al., 2013; Zhu et al., 2014), temperature plus heating rate (Angin, 2013), and pyrolysis duration (Cimò et al., 2014; Zhang et al., 2015). However, the effect of different pyrolysis atmospheres for biochar production has been mostly neglected. Compared with a no-oxygen pyrolysis atmosphere, the biochar yield, volatile matter and functional groups are significantly influenced by the presence of oxygen in the pyrolysis atmosphere (Luo et al., 2015). The number of oxygenated groups, carboxyl, phenolic, and ether groups, were rich at low pyrolysis temperature under anoxic conditions (Zhu et al., 2014). Therefore, the changes of oxygenated functional groups should be determined in a low oxygen pyrolysis atmosphere. Biochars formed under gasification usually have an oxygen-containing atmosphere and can exhibit a high mineral content, which could promote the heavy metals adsorption capacity (Inyang and Dickenson, 2015). In addition, Liu et al. (2015) indicated heat treatment at low temperatures under a weak oxidizing atmosphere may create more oxygenated functional groups. However, very little research has focused on establishing the relationship between $\mathrm{Pb}^{2+}$ or $\mathrm{Cd}^{2+}$ sorption and biochar properties based on different pyrolysis atmospheres (Luo et al., 2015). Therefore, further effort is required to examine the exact mechanisms of heavy metal sorption on biochars produced under different pyrolysis conditions.

In this research, biochars were obtained under a $0-4 \%$ oxygen content atmosphere through slow pyrolysis of Phyllostachys pubescens (PP) at $450{ }^{\circ} \mathrm{C}$ and $700{ }^{\circ} \mathrm{C}$, and the physicochemical properties of samples were characterized. The objectives were to: (1) determine the sorption capacity of $\mathrm{Pb}^{2+}$ and $\mathrm{Cd}^{2+}$ on biochars produced under different pyrolysis atmospheres; (2) investigate the surface properties of biochar produced under pyrolysis atmospheres with different oxygen contents; and (3) compare the different mechanisms of $\mathrm{Pb}^{2+}$ and $\mathrm{Cd}^{2+}$ removal from water by the biochars on a qualitative and quantitative basis. This study could help to support the use of macroporous, low cost PP biochar for $\mathrm{Pb}^{2+}$ and $\mathrm{Cd}^{2+}$ removal from mainstream wastewater treatment.

\section{Methods}

\subsection{Preparation of biochar samples}

The biomass materials of pubescens (Phyllostachys, Indosasa McClure) were used as feedstocks for biochar production. Phyllostachys pubescens are mainly distributed in the south of the Yangtze River of China, and 85\% of the PP in the world are located in this region. The PP were collected in Binzhou, Hunan Province,
China, and subsequently washed with ultrapure water three times to remove attached dust, and then dried at $80^{\circ} \mathrm{C}$ for more than $24 \mathrm{~h}$.

The biochar samples used in this study were produced by slowly pyrolyzing the dried PP in a lab-scale quartz tube furnace (OTF-1200X-80, Hefei Kejing, China) with a trace gases mixed gas supply system (CGM-2F, Hefei Kejing, China) under the varying conditions shown in Table 1 . The samples were placed in a tubular furnace and air was evacuated. A gas mixture, with a set oxygen and nitrogen flow ratio (Table 1 ), was passed through the tubular furnace. The process of evacuating the furnace and passing through the mixed gas was repeated, and the process took about $60 \mathrm{~min}$ in total. The gas mixture was continuously supplied during the pyrolysis process, with gas flow maintained at $0.4 \mathrm{~L} \mathrm{~min}^{-1}$. The reactor was heated with a heating rate of $20^{\circ} \mathrm{C} \mathrm{min}^{-1}$. These biochars were cooled to room temperature under the predetermined atmospheric conditions. The resultant PP biochars were ground through 120$180-\mu \mathrm{m}$ (80-120 mesh) sieves. Finally, the PP biochars were stored in scintillation vials with polypropylene caps and polyethylene liners in the dark until required for the sorption experiment.

\subsection{Batch sorption experiment}

The $\mathrm{Pb}(\mathrm{II})$ and $\mathrm{Cd}(\mathrm{II})$ solution was prepared using $\mathrm{Pb}\left(\mathrm{NO}_{3}\right)_{2}$ and $\mathrm{Cd}\left(\mathrm{NO}_{3}\right)_{2} \cdot 2 \mathrm{H}_{2} \mathrm{O}$ (Guaranteed reagent, Sigma-Aldrich, USA). All the tested $\mathrm{Pb}(\mathrm{II})$ and $\mathrm{Cd}(\mathrm{II})$ solutions contained $5 \mathrm{mM} \mathrm{NaNO}_{3}$ as the background electrolyte to maintain ionic strength, and the $\mathrm{pH}$ was pre-adjusted to $5.0 \pm 0.05$ by adding either $0.1 \mathrm{M} \mathrm{HNO}_{3}$ or $\mathrm{NaOH}$ solutions before testing. Next, $2 \mathrm{~g} \cdot \mathrm{L}^{-1}$ of PP biochars were added to $50-\mathrm{mL}$ vials at an initial concentration of $100 \mathrm{mg} \cdot \mathrm{L}^{-1}$ for both $\mathrm{Cd}(\mathrm{II})$ and $\mathrm{Pb}(\mathrm{II})$. The vials were shaken at $140 \mathrm{rpm}$ and obtain the sample from 0 to $50 \mathrm{~h}$ to determine $\mathrm{Cd}(\mathrm{II})$ and $\mathrm{Pb}$ (II) in the liquid phase to analyze the adsorption kinetics. Adsorption isotherms were produced with the initial $\mathrm{Cd}(\mathrm{II})$ and $\mathrm{Pb}(\mathrm{II})$ concentration in the range of $100-800 \mathrm{mg} \cdot \mathrm{L}^{-1}$. All vials were shaken at $140 \mathrm{rpm}$ at $25{ }^{\circ} \mathrm{C}$ for $24 \mathrm{~h}$. After shaking, all mixtures were filtered through a $0.22-\mu \mathrm{m}$ Millipore filter. The influence of coexisting ions on adsorption was studied at appropriate $\mathrm{pH}$ with the addition of different concentrations of $\mathrm{Ca}^{2+}\left(0-30 \mathrm{mg} \cdot \mathrm{L}^{-1}\right)$ and $\mathrm{Fe}^{3+}(0-$ $\left.30 \mathrm{mg} \cdot \mathrm{L}^{-1}\right) . \mathrm{K}^{+}\left(0-30 \mathrm{mg} \cdot \mathrm{L}^{-1}\right), \mathrm{NH}_{4}^{+}\left(0-50 \mathrm{mg} \cdot \mathrm{L}^{-1}\right)$, humic acid (HA; $\left.\quad 0-100 \mathrm{mg} \cdot \mathrm{L}^{-1}\right), \quad \mathrm{Cd}^{2+}\left(0-1.5 \mathrm{mmol} \cdot \mathrm{L}^{-1}\right), \quad$ or $\mathrm{Pb}^{2+}(0-$ $\left.1.5 \mathrm{mmol} \cdot \mathrm{L}^{-1}\right)$. The impact of $\mathrm{pH}$ on biochar adsorption was examined by adjusting the $\mathrm{pH}$ of the initial $\mathrm{Cd}^{2+}$ or $\mathrm{Pb}^{2+}$ solutions ( $\left.100 \mathrm{mg} \mathrm{L}^{-1}\right)$ to ensure equilibrium solution ranging from 2.0 to 7.0, because precipitates are formed under high solution $\mathrm{pH}$. The $\mathrm{Cd}(\mathrm{II})$ and $\mathrm{Pb}(\mathrm{II})$ concentrations in the filtrate were analyzed with a flame atomic absorption spectrophotometer (Z-5000, Hitachi, Japan) at 229.0 and $283.3 \mathrm{~nm}$, respectively. The experiments were performed in triplicate, with appropriate blanks without biochar samples or without heavy metals. As the mass loss was negligible, sorption of solutes by biochars was determined by mass balance.

\subsection{Sorption mechanisms}

\subsubsection{Biochar characterization}

The specific surface area was determined by using Bru nauer-Emmett-Teller isotherm method and the pore volume was estimated using the Barrett-Joyner-Halenda method at $77 \mathrm{~K}$ (Quantachrome Nova 3200e, USA) with a $\mathrm{N}_{2}$ adsorption-desorption. The surface structure and elemental content distribution of the biochars were analyzed using scanning electron microscopy (SEM; S-4800, Hitachi, Japan) and energy-dispersive X-ray spectroscopy (EDX; 7593-H, Horiba, Japan). The $\mathrm{pH}$ of samples was measured in a suspension of 1:10 sample/deionized water using a combination electrode. The suspension was shaken for $1 \mathrm{~h}$ before measurement. The existence and crystalline form of chemical pre- 
Table 1

Biochar preparation conditions ( $\mathrm{A}$ is the pyrolysis temperature, $\mathrm{B}$ is the pyrolysis time, $C$ is the oxygen content in the pyrolysis atmosphere, expressed as the oxygen to nitrogen gas content ratio, $\mathrm{D}$ is the raw material particle size).

\begin{tabular}{lllll}
\hline Sample & $\mathrm{A}\left({ }^{\circ} \mathrm{C}\right)$ & $\mathrm{B}(\mathrm{h})$ & $\mathrm{C}(\%)$ & $\mathrm{D}(\mu \mathrm{m})$ \\
\hline P1 & 450 & 3 & 0 & $106-150$ \\
P2 & 450 & 3 & 1 & $106-150$ \\
P3 & 450 & 3 & 2 & $106-150$ \\
P4 & 450 & 3 & 4 & $106-150$ \\
P5 & 700 & 3 & 0 & $106-150$ \\
P6 & 700 & 3 & 1 & $106-150$ \\
P7 & 700 & 3 & 4 & $106-150$ \\
\hline
\end{tabular}

cipitates after $\mathrm{Pb}^{2+}$ and $\mathrm{Cd}^{2+}$ sorption were checked using a $\mathrm{D} / \mathrm{Max}-$ IIIA powder X-ray diffractometer (Rigaku Corp., Japan). The patterns were collected in the angular range from $5^{\circ}$ to $60^{\circ}$ with $0.02^{\circ}$ step size. The solid phases were identified using the Jade 5.0 software (Materials Data Inc., Livermore, CA, USA). The surface charge properties of biochars were evaluated by zeta potential measurements, which were conducted at different equilibrium $\mathrm{pH}$ using an electroacoustic spectrometer (ZEN3600 Zetasizer, $\mathrm{UK})$. The isoelectric point $\left(\mathrm{pH}_{\text {IEP }}\right)$ of the biochars, defined as the $\mathrm{pH}$ value at which the electrokinetic potential equals zero, was determined by plotting zeta potentials against pH (Fang et al., 2014). The elemental (C, H, N) analyses were performed with an Elemental Analyzer (Elementar Vario EL III instrument, Germany).

Qualitative analysis of oxygen functional groups used Fourier transform infrared spectroscopy (FTIR) and X-ray photoelectron spectroscopy (XPS). The FTIR data were recorded in the 4000$400 \mathrm{~cm}^{-1}$ region with a Thermo Nicolet FTIR spectrophotometer (model 6700) using $\mathrm{KBr}$ pellets. The XPS experiments were carried out on a Thermo Scientific Escalab 250Xi instrument equipped with $\mathrm{Al} \mathrm{Ka}$ radiation $(\mathrm{hv}=1486.6 \mathrm{eV})$. Binding energies for the high-resolution spectra were calibrated by setting $C 1 \mathrm{~s}$ at $284.8 \mathrm{eV}$. The XPS core level spectra were analyzed using XPS Peak 4.1. Quantitative analysis of oxygenated acidic groups and basic components for samples were determined using Boehm titration method (Goertzen et al., 2010; Oickle et al., 2010). A more detailed account of Boehm titration is available in the Supporting Information.

\subsubsection{Quantitative analysis of different mechanisms to $\mathrm{Pb}^{2+}$ or $\mathrm{Cd}^{2+}$ sorption}

The calculation of the contribution of different mechanisms to $\mathrm{Pb}^{2+}$ and $\mathrm{Cd}^{2+}$ sorption on biochars has been reported (Cui et al., 2016; Wang et al., 2015). The calculation method of the sorption attributed to precipitation with minerals (Qp), oxygen functional groups complications (Qf) and coordination of heavy metals with $\pi$ electrons $\left(\mathrm{Cd}^{2+}-\pi\right.$ or $\left.\mathrm{Pb}^{2+}-\pi\right)$ interaction $(\mathrm{Q} \pi)$ was as follows: (a) most ash from the PP biochars were removed by the acid dipping procedure in the supporting information, and the oxygencontaining functional groups were not changed. The reduced amount of heavy metals sorption on the biochars before and after demineralization could be considered as the contribution of the removed minerals, which was calculated as shown in Eq. (1); (b) when the biochars were washed with acid, a decrease in $\mathrm{pH}$ before and after $\mathrm{Pb}^{2+}$ or $\mathrm{Cd}^{2+}$ sorption on acid-washed PP biochars occurred as a result of the complication with the oxygencontaining organic groups. The $\mathrm{pH}$ change as an indicator for the calculation of oxygen containing group effect has been reported in a previous paper and the operation method was based on (Wang et al., 2015). Moreover, the carboxyl and hydroxyl groups of biochar release $\mathrm{H}^{+}$ions by exchange interactions, which could result in $\mathrm{pH}$ changes in the solution (Cao et al., 2009; Mohan et al., 2007). The $\mathrm{pH}$ decrease was used as an indicator of the amount of $\mathrm{H}^{+}$release, thereby calculating the adsorbed $\mathrm{Pb}^{2+}$ by the oxygen-containing functional groups complexation (Qf). (c) The amount of sorbed $\mathrm{Pb}^{2+}$ or $\mathrm{Cd}^{2+}$ on biochar after the acid dipping procedure $(\mathrm{Qa})$ was taken as the result of the $\pi$ interaction and functional groups complexation together. Therefore, the amount of $\mathrm{Q} \pi$ could be calculated as shown in Eq. (2). The contribution percentage of different mechanisms to the overall $\mathrm{Pb}^{2+}$ and $\mathrm{Cd}^{2+}$ sorption was then calculated using the $\mathrm{Qf} / \mathrm{Qt}, \mathrm{Q} \pi / \mathrm{Qt}$ and $\mathrm{Qp} / \mathrm{Qt}$ ratio.

$\mathrm{Qp}=\mathrm{Qt}-\mathrm{Qa}$,

$\mathrm{Q} \pi=\mathrm{Qa}-\mathrm{Qf}$,

where $\mathrm{Qp}$ is the amount of $\mathrm{Pb}^{2+}$ or $\mathrm{Cd}^{2+}$ sorption attributed to the precipitation with minerals, $\mathrm{Qt}$ is the total sorption of $\mathrm{Pb}^{2+}$ or $\mathrm{Cd}^{2+}$ on biochar, $\mathrm{Qa}$ is the amount of sorbed $\mathrm{Pb}^{2+}$ or $\mathrm{Cd}^{2+}$ on biochar after the acid dipping procedure, $\mathrm{Q} \pi$ is the amount of $\mathrm{Pb}^{2+}$ sorption resulting from $\mathrm{Pb}^{2+}-\pi$ interaction, and $\mathrm{Qf}$ is the oxygen functional groups complications.

\subsection{Statistical analysis of the experimental data}

The kinetics of $\mathrm{Pb}^{2+}$ or $\mathrm{Cd}^{2+}$ sorption on biochars were simulated using pseudo first order kinetic equation (Eq. (3)), pseudo second order kinetic model (Eq. (4)), intraparticle diffusion model (inner model, Eq. (5)) and Elovich model (Eq. (6)), which can be presented as follows (Inyang et al., 2012; Wang et al., 2015):

$Q_{t}=Q_{e}\left(1-e^{-k_{1} t}\right)$

$Q_{t}=\frac{k_{2} Q_{e}^{2} t}{1+k_{2} Q_{e} t}$

$Q_{t}=k_{3} t^{0.5}+b$

$Q_{t}=\frac{1}{\beta} \ln (\alpha \beta t+1)$

where Qt ( $\mathrm{mg} \mathrm{g}^{-1}$ ) and Qe ( $\mathrm{mg} \mathrm{g}^{-1}$ ) are the amounts of metals sorbed at time $t$ and at equilibrium, respectively. $\mathrm{k}_{1}$ is the pseudo first order rate constant $\left(h^{-1}\right), k_{2}$ is the rate constant of the pseudo second order adsorption $\left(\mathrm{g} \mathrm{mg}^{-1} \mathrm{~h}^{-1}\right), \mathrm{k}_{3}$ is the intraparticle diffusion rate constant $\left(\mathrm{mg} \mathrm{g}^{-1} \mathrm{~h}^{-0.5}\right), \mathrm{b}$ is the intercept $\left(\mathrm{mg} \mathrm{g}^{-1}\right), \alpha$ $\left(\mathrm{mg} \mathrm{g}^{-1} \mathrm{~h}^{-1}\right)$ is the initial adsorption rate, and $\beta\left(\mathrm{g} \mathrm{mg}^{-1}\right)$ is the desorption constant at time t.

Langmuir (Eq. (7)) and Freundlich (Eq. (8)) models were used to fit the $\mathrm{Pb}^{2+}$ or $\mathrm{Cd}^{2+}$ adsorption isotherm data (Kołodyńska et al., 2012):

$Q_{e}=\frac{Q_{m} K_{L} C_{e}}{1+K_{L} C_{e}}$

$Q_{e}=K_{F} C_{e}^{n}$

where $C_{e}$ is the equilibrium aqueous concentration of metals ( $m g$ $\mathrm{L}^{-1}$ ). The parameters $\mathrm{K}_{\mathrm{L}}$ and $\mathrm{K}_{\mathrm{F}}$ are the adsorption coefficients of Langmuir and Freundlich $\left(\mathrm{L} \mathrm{mg}^{-1}\right.$ and $\left.\left(\mathrm{mg} \mathrm{g}^{-1}\right)\left(\mathrm{mg} \mathrm{L}^{-1}\right)^{-\mathrm{n}}\right)$, respectively. $\mathrm{Q}_{\mathrm{m}}$ is the maximum adsorption capacity of the solute (mg $\mathrm{g}^{-1}$ ). The $\mathrm{n}$ is the Freundlich constant related to the surface site heterogeneity.

In this study, the experiments of kinetics and adsorption isotherms were conducted in triplicate. Significant differences were tested using Duncan's multiple range test $(P=0.05)$ by SPSS 17.0. The kinetics and adsorption isotherms were fitted using Origin Pro 8.0 (Origin Lab, USA). 


\section{Results and discussion}

\subsection{Adsorption kinetics and adsorption isotherms}

As shown in Fig. 1, the adsorption for $\mathrm{Cd}^{2+}$ or $\mathrm{Pb}^{2+}$ was rapid adsorption in the first $8 \mathrm{~h}$, and the adsorption capacity of $\mathrm{Pb}^{2+}$ and $\mathrm{Cd}^{2+}$ reached $98.9 \%$ and $99.8 \%$ of adsorption equilibrium capacity at $24 \mathrm{~h}$, respectively. The correlation coefficient $\left(R_{2}\right)$ of the Elovich model was higher than that of other models (Table S1), indicating that the experimental data fitted better to the Elovich model, which is similar to adsorption of $\mathrm{Zn}$ (II) to a meat and bone meal biochar (Betts et al., 2013). For biochar P5, the initial adsorption rate $(\alpha)$ of the Elovich model for $\mathrm{Pb}^{2+}$ was 9.43 times greater than that for $\mathrm{Cd}^{2+}$. The Elovich equation has been used to infer a number of transport-limited reaction mechanisms, including bulk and surface diffusion (Cheung et al., 2000). The Elovich model describes reactions that are biphasic, with an initial, rapid reaction followed by a slower progress. This has been observed in other sorption reactions and may imply reactions limited by diffusion (Betts et al., 2013). Cheung et al. (2000) described heavy metal sorption on biochar with the Elovich model and inferred from the results that the mechanism of metals sorption was limited by diffusion through pores in the biochar.

The sorption isotherms of $\mathrm{Pb}(\mathrm{II})$ and $\mathrm{Cd}(\mathrm{II})$ onto PP biochar are presented in Fig. 1 and the fitting parameters of are listed in Table S2. The adsorption amounts of $\mathrm{Cd}(\mathrm{II})$ and $\mathrm{Pb}$ (II) of the material both increased rapidly in the low concentration range, and then increased gradually as the initial concentrations increased. The correlation coefficient values $\left(R_{\mathrm{adj}}^{2}>0.94\right)$ demonstrate that the Freundlich model is more suitable than the Langmuir model for describing the adsorption process.

The Freundlich adsorptive capacity $\left(\mathrm{K}_{\mathrm{f}}\right)$ for $\mathrm{Cd}(\mathrm{II})$ and $\mathrm{Pb}(\mathrm{II})$ increased substantially with oxygen content increase at low pyrolysis temperature, but the adsorption capacity of the PP biochar showed little change with oxygen content increase at $700{ }^{\circ} \mathrm{C}$. In particular, $\mathrm{Q}_{\max }$ increased dramatically from the P1 to P4 samples, possibly due to the considerable increase in surface area with the trace oxygen atmosphere, which may have enhanced the number of adsorption sites. For each sample, the adsorption capacity for $\mathrm{Pb}(\mathrm{II})$ was larger than that for $\mathrm{Cd}(\mathrm{II})$. The maximum adsorption capacity of $\mathrm{Pb}(\mathrm{II})$ reached $67.45 \mathrm{mg} \cdot \mathrm{L}^{-1}$ with $\mathrm{P} 6$, whereas it reached $14.68 \mathrm{mg} \cdot \mathrm{L}^{-1}$ for Cd(II) with P5 (Table S2). Compared with other adsorbent materials, PP biochar demonstrates the potential to act as an effective adsorbent for $\mathrm{Pb}^{2+}$ removal in aqueous solution; however, PP biochar shows a poor adsorption capacity for $\mathrm{Cd}^{2+}$ (Table S3).

The regeneration property of the as-synthesized biochar was also studied, and the results of the regeneration tests are shown in Fig. S1. For the biochar regeneration, metal-adsorbed biochar was washed in $200 \mathrm{~mL}$ of a $0.1 \mathrm{~N} \mathrm{HNO}_{3}$ solution and gently stirred for $1 \mathrm{~h}$. In the regeneration trials, the adsorption capacity decreased for $\mathrm{Cd}^{2+}$ or $\mathrm{Pb}^{2+}$ adsorption. The adsorption capacity of $\mathrm{Pb}^{2+}$ and $\mathrm{Cd}^{2+}$ was $68.5-72.3 \%$ and $74.3-81.5 \%$ of the origin biochar, respectively. These reductions in adsorption capacity were largely due to the structural deterioration and surface mineral loss of the adsorbents.

\subsection{Effect of $\mathrm{pH}$ and coexisting ions on the adsorption of $\mathrm{Cd}(\mathrm{II})$ and $\mathrm{Pb}$} (II)

The zeta potential is representative of the surface charge property of a particle interacting with other particles or ions in the surrounding suspension (Yao et al., 2016). Fig. 2a illustrates the zeta potential curves of biochars at different solution $\mathrm{pH}$ values. The obtained $\mathrm{pH}_{\text {IEP }}$ values were $2.1,1.7,1.2,1.5$ and 1.5 for P1, P3,
P4, P6 and P7, respectively. The $\mathrm{pH}_{\mathrm{IEP}}$ value of the biochar is higher at high pyrolysis temperature, which was similarly shown for a biochar derived from hardwood litter (Teixidó et al., 2011). Some studies have shown $\mathrm{PH}_{\mathrm{IEP}}$ of biochar is within the range of 1-2.5 (Ding et al., 2016; Fang et al., 2014). The pH-dependent curve of the zeta potential displayed a horizontal S-shape with two significant inflection points $\left(\mathrm{pH}_{\mathrm{a}}\right.$ and $\left.\mathrm{pH}_{\mathrm{b}}\right)$, which is similar to the observation by Fang et al. (2014). Their results demonstrated that a platform appeared at pH 5-9 for biochar produced at low pyrolysis temperatures, whereas the platform occurred at $\mathrm{pH}$ 6-10 for biochar produced at high pyrolysis temperatures (Fang et al., 2014). There were two different types of $\mathrm{pH}$-dependent functional groups on biochars, carboxyl and hydroxyl groups, which influenced zeta potential at two distinct pH ranges (Fang et al., 2014; Shokri et al., 2012). The zeta potentials of biochars (Fig. 2a) indicate that the surfaces of these biochars were mostly negatively charged. The carboxyl and hydroxyl groups on the biochar act as a buffer substance, retaining a relatively stable zeta potential in the tested $\mathrm{pH}$ range from 3.3 to 6.2 .

The $\mathrm{pH}$ is a major factor affecting adsorption of $\mathrm{Cd}(\mathrm{II})$ and $\mathrm{Pb}(\mathrm{II})$ in aqueous solutions (Fig. 2 b). When the solution $\mathrm{pH}>\mathrm{pH}_{\text {IEP }}$, biochar conducts electric adsorption with metal cations, including $\mathrm{Cd}(\mathrm{II})$ and $\mathrm{Pb}(\mathrm{II})$, due to the deprotonation of the adsorbent hydrated surface. The $\mathrm{Cd}^{2+}$ adsorption capacity slightly increased from 12.8 to $21.2 \mathrm{mg} \cdot \mathrm{L}^{-1}$ when $\mathrm{pH}$ increased from 5 to 7 , which may result from increase in the electrostatic attraction capacity, as zeta potential varied from -25.5 to $-32.2 \mathrm{mV}$. The surface charge properties have an important influence on the adsorption capability and mechanism of heavy metals adsorption onto biochars. When the initial $\mathrm{pH}$ is higher (5-7), the $\mathrm{pH}$ after equilibrium can be improved by the $\mathrm{pH}$ buffer capacity of biochar, and the heavy metals subsequently precipitate (Chen et al., 2014). When the $\mathrm{pH}$ is lower, only limited local precipitation occurs because the large number of $\mathrm{H}^{+}$ions compete with these divalent metal ions, weakening the adsorption performance at the lower initial pH (Lu et al., 2012).

As shown in Fig. $\mathrm{S} 2, \mathrm{~K}^{+}$had little influence on $\mathrm{Cd}^{2+}$ and $\mathrm{Pb}^{2+}$ removal until the concentration of $\mathrm{K}^{+}$exceeded 8 and $20 \mathrm{mg} \cdot \mathrm{L}^{-1}$, respectively. A slight influence of $\mathrm{NH}_{4}^{+}$on $\mathrm{Cd}^{2+}$ and $\mathrm{Pb}^{2+}$ adsorption was observed (Fig. S2). However, the HA, which was calculated as total organic carbon, had a sensitive influence on $\mathrm{Pb}^{2+}$ removal, and the removal capacity reduced from 38.5 to $28.4 \mathrm{mg} \cdot \mathrm{g}^{-1}$ while the content of HA was $2 \mathrm{mg} \cdot \mathrm{L}^{-1}$. Similar results were obtained with cadmium adsorption. This could be attributed to complexation of $\mathrm{HA}$ with $\mathrm{Cd}^{2+}$ or $\mathrm{Pb}^{2+}$ which could hinder the electrostatic energy between the charges on biochar surface and heavy metal ions in aqueous solution. A high concentration of $\mathrm{K}^{+}$and $\mathrm{NH}_{4}^{+}$in aqueous solution could preempt surface adsorption sites of adsorbents, such as oxygen functional groups, which could decrease the adsorption capacity of $\mathrm{Cd}^{2+}$ and $\mathrm{Pb}^{2+}$. As shown in Fig. S2, $\mathrm{Ca}^{2+}$ and $\mathrm{Mn}^{2+}$ have little influence on heavy metals removal. $\mathrm{Ca}^{2+}$ and $\mathrm{Mn}^{2+}$ could precipitate with minerals, such as carbonate, which may compete with heavy metal removal. The stability constants (pKsp) of $\mathrm{CdCO}_{3}$ (pKsp: 12.00) and $\mathrm{PbCO}_{3}$ (pKsp: 13.13) were higher than those of $\mathrm{CaCO}_{3}$ (pKsp: 8.54) and $\mathrm{MnCO}_{3}$ (pKsp: 10.04). Therefore, it can be speculated that $\mathrm{Cd}^{2+}$ or $\mathrm{Pb}^{2+}$ was more likely to precipitate than $\mathrm{Ca}^{2+}$ and $\mathrm{Mn}^{2+}$. Moreover, the high ionic strength of the solution could influence the activity coefficient of heavy metals, thus decreasing the collisions and contact between the sorbent and solute (Ding et al., 2016).

The effect of coexisting $\mathrm{Pb}^{2+}$ on the adsorption of $\mathrm{Cd}^{2+}$, and vice versa, was also evaluated (Fig. S3). In comparison with the single system, the coexistence of $\mathrm{Pb}^{2+}$ and $\mathrm{Cd}^{2+}$ could strongly influence the adsorption capacity of $\mathrm{Cd}^{2+}$, but had little effect on $\mathrm{Pb}^{2+}$ adsorption. Adsorption capacity for $\mathrm{Cd}^{2+}$ decreased from $51 \mathrm{mmol} \mathrm{\textrm {kg } ^ { - 1 }}$ with no $\mathrm{Pb}^{2+}$ present to $3 \mathrm{mmol} \mathrm{kg}^{-1}$ with $0.5 \mathrm{mM} \mathrm{Pb}^{2+}$. The initial 

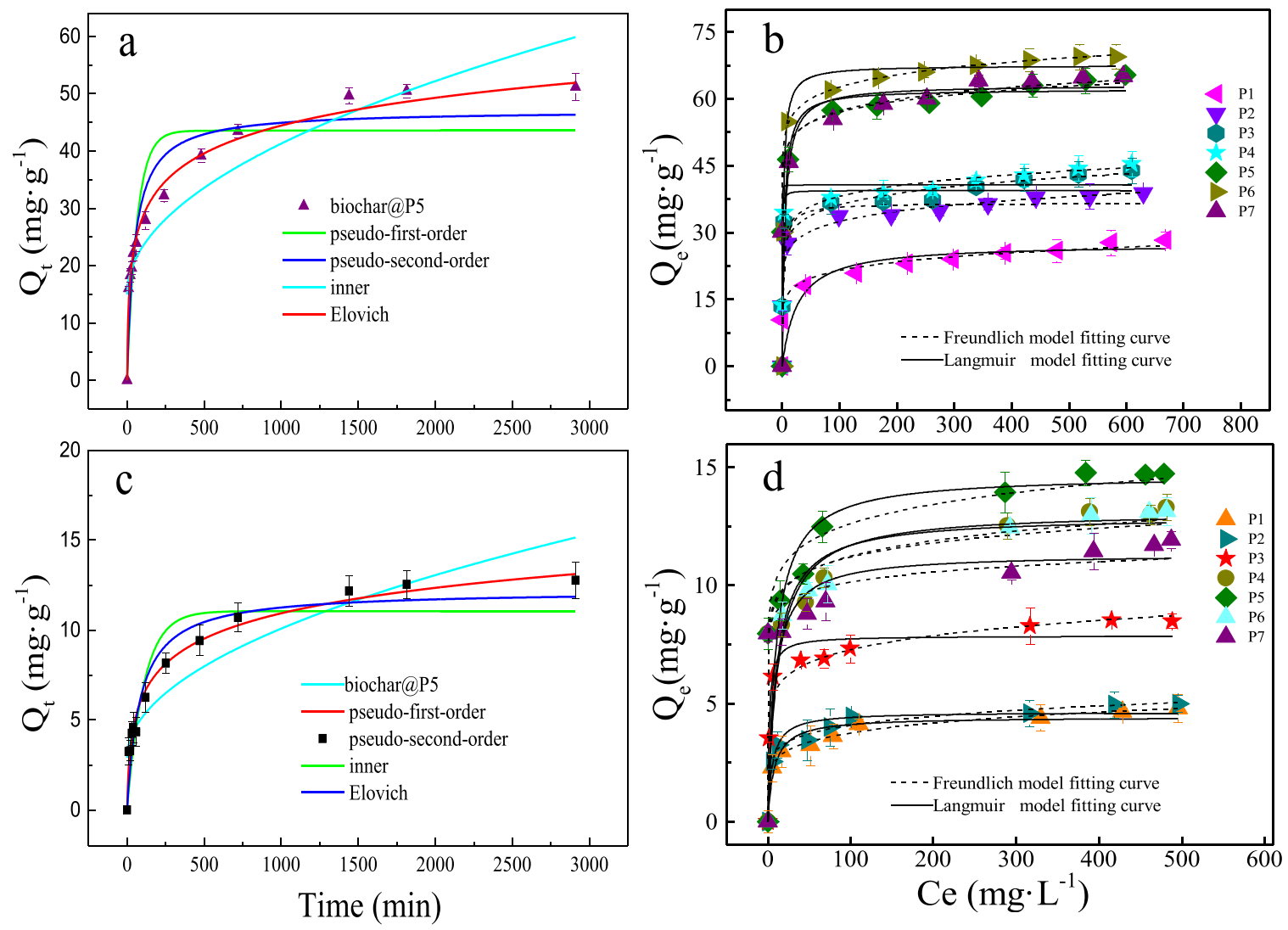

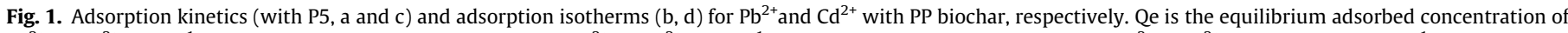

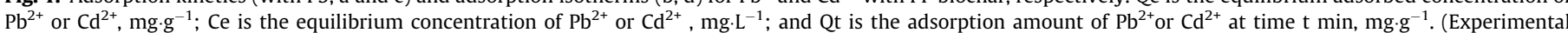

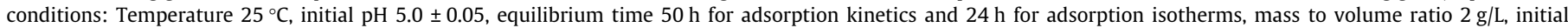
concentration of $100-800 \mathrm{mg} \cdot \mathrm{L}^{-1}\left(\mathrm{~Pb}^{2+}\right)$ and $50-600 \mathrm{mg} \cdot \mathrm{L}^{-1}\left(\mathrm{Cd}^{2+}\right)$, stirring $140 \mathrm{rpm}$.)

concentration of $\mathrm{Cd}^{2+}$ was $1.5 \mathrm{mM}$. This indicates that the adsorption process in binary systems was more favorable for $\mathrm{Pb}^{2+}$, supporting the findings of earlier research (Ding et al., 2016). Inhibition of adsorption with $\mathrm{Cd}^{2+}$ in binary systems may be attributed to the prior interactions between $\mathrm{Pb}^{2+}$ and oxygen-containing functional groups, and the stronger complexion capacity of $\mathrm{Pb}^{2+}$ with negative charge (Ding et al., 2016; Jin and Bai, 2002; Ma and Dougherty, 1997).

\subsection{Characteristics of biochars}

The PP biochar was characterized by FTIR spectroscopy (Fig. S4). Pyrolysis temperature and oxygen atmosphere both influence the number of functional groups on the biochar. Compared with biochar produced at $450^{\circ} \mathrm{C}$, fatty hydrocarbon (2853 and $2923 \mathrm{~cm}^{-1}$ ) and other aliphatic functional groups (1210$1591 \mathrm{~cm}^{-1}$ ) were gradually weakened and diminished at $700{ }^{\circ} \mathrm{C}$. This was accompanied by an increase in volatile organic matter and an increase of the content of aromatic structures after dehydrogenation of carbohydrates (Dong et al., 2013; Fang et al., 2014). As the temperature increased, the number of oxygencontaining functional groups gradually decreased. With increasing oxygen content atmosphere at low pyrolysis temperature $\left(450^{\circ} \mathrm{C}\right)$, the number of lactonic functional groups and micropore volume content of PP biochar increased alongside the surface area (Table 2). A new peak at $1690 \mathrm{~cm}^{-1}$ representing lactonic $\mathrm{C}=0$ groups was consistent with condensation of biochar structure under a $2 \%$ and $4 \%$ oxygen content pyrolysis atmosphere at $450^{\circ} \mathrm{C}$ (Fig. S4). As shown in Fig. S5, XRD spectra of the pre-sorption biochars indi- cated the existence of calcite $\left(\mathrm{CaCO}_{3}\right)$ in PP biochars, which could be a source of carbonate release into the solution. Minerals such as Fairchildite, Whewellite, and Calcitecalcite have also been found in other biochars converted from raw material (Wang et al., 2015; Zhu et al., 2014).

The Raman spectra were also used to analyze the aromatization of PP biochars (Fig. S6). All of the curves exhibited two relatively broad Raman bands with Raman shifts at $1340-1357 \mathrm{~cm}^{-1}$ and $1589-1598 \mathrm{~cm}^{-1}$, which corresponded to the D-band and Gband, respectively. The biochar synthesized at low and high temperature both clearly exhibited two peaks, which indicates the presence of amorphous graphite and graphitic crystallites. The Elemental $(\mathrm{C}, \mathrm{H}, \mathrm{N})$ analyses of the biochar were also conducted. As shown in Table S4, the results indicated that the carbon content of biochar synthesized at low-temperature varied from $77.24 \%$ to $81.32 \%$. The molar ratios of elements were calculated to estimate the aromaticity $(\mathrm{H} / \mathrm{C})$ and polarity $(\mathrm{O} / \mathrm{C}, \mathrm{O}+\mathrm{N} / \mathrm{C})$ of the biochar. The results indicate higher aromaticity and lower polarity with oxygen content increase.

The FTIR technique is useful for identifying types of chemical bonds in a molecule based on the infrared absorption spectrum, whereas XPS is a surface sensitive technique that measures elemental composition and chemical state in a material. The XPS C1s peaks of P1, P2 and P4 are presented in Fig. S4, which clearly shows that the oxygen groups were prevalent on the surface of biochars. The main peak for the C1s spectra was assigned to graphitic and aromatic carbon at $284.6 \mathrm{eV}$, phenolic hydroxyl or ether groups at $285.5-286.2 \mathrm{eV}$, and carboxylic or ester groups at $288.5-288.8 \mathrm{eV}$. The relative percentages of oxygen-containing 

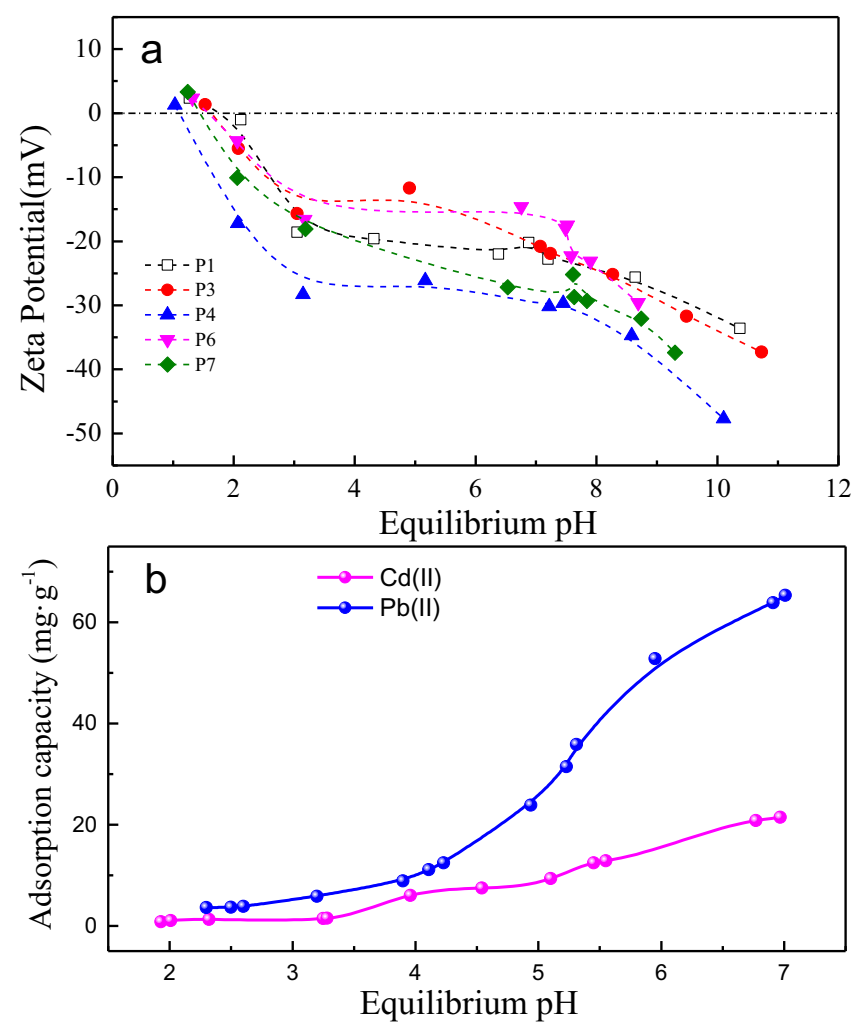

Fig. 2. (a) Zeta potentials of PP biochar at different solution pH values. (b) Effect of equilibrium solution $\mathrm{pH}$ values on $\mathrm{Cd}$ (II) and $\mathrm{Pb}$ (II) adsorption by $\mathrm{P} 4$. (Solution volume: $30 \mathrm{~mL}$; adsorbent dose: $2 \mathrm{~g} \cdot \mathrm{L}^{-1}$; initial concentration: $100 \mathrm{mg} \mathrm{L}^{-1}$; contact time: $24 \mathrm{~h})$.

groups on PP biochars are listed in Table S5. With the increase of pyrolysis oxygen content at $450{ }^{\circ} \mathrm{C}, \mathrm{C}-\mathrm{O}$ declined from $29.4 \%$ for $\mathrm{P} 1$ to $22.6 \%$ for $\mathrm{P} 2$ and $12.6 \%$ for $\mathrm{P} 4$, but the content of $\mathrm{C}=\mathrm{O}$ or $\mathrm{O}-\mathrm{C}=\mathrm{O}$ increased, which supports the findings of previous research (Harvey et al., 2012). As shown in Table 2, PP biochars produced with oxygen atmosphere at lower temperature contained more lactonic functional groups, which is consistent with XPS data (Table S5). The surface functional groups (e.g., carboxylic, lactonic and phenolic) were adsorption sites for heavy metals (Chen et al., 2015; Lu et al., 2012).

Table 2 presents the oxygen-containing functional groups and total alkalis from the Boehm titration. Lactonic groups sharply increased with promotion oxygen content atmosphere at $450{ }^{\circ} \mathrm{C}$, while other acid functional groups (carboxylic and phenolic) and total basicity were little affected by the oxygen content. However, the total basicity increased with increasing pyrolysis temperature, due to the increasing contents of ash and basic functional groups. Total acidity showed opposite trends to basicity at $700{ }^{\circ} \mathrm{C}$. The organic acids, including carboxylic, lactonic and phenolic acids, decreased and gradually disappeared at high pyrolysis temperature. Table S4 shows the yield and ash content for the PP biochar.
Yields declined gradually with the oxygen content from $0 \%$ to $4 \%$, because of the accelerated decomposition of the components of biochar, producing ash. Correspondingly, the ash content considerably increased as the oxygen atmosphere increased and finally stabilized at $22.4 \%$ at $450{ }^{\circ} \mathrm{C}$ and $25.5 \%$ at $700{ }^{\circ} \mathrm{C}$. Ash on the biochar surface is composed of various inorganic compounds, such as carbonate, which could precipitate with $\mathrm{Pb}^{2+}$ and $\mathrm{Cd}^{2+}$ and improve the heavy metal adsorption capacity.

\subsection{Possible mechanisms for $\mathrm{Cd}(\mathrm{II})$ and $\mathrm{Pb}(\mathrm{II})$ adsorption on biochars}

To determine the possible mechanisms for $\mathrm{Cd}(\mathrm{II})$ and $\mathrm{Pb}(\mathrm{II})$ adsorption on biochars, XPS analysis was employed to identify the type of heavy metal adsorption on the biochar surface (Tang et al., 2015). The XPS was used to analyze the changes in binding energy of $\mathrm{C} 1 \mathrm{~s}$ and $\mathrm{O} 1 \mathrm{~s}$ in PP biochar before and after adsorption for $\mathrm{Pb}(\mathrm{II})$ and $\mathrm{Cd}(\mathrm{II})$ (Fig. S7). After adsorption, new peaks were observed that originated from the binding energy spectrum of $\mathrm{Pb} 4 \mathrm{f}$ and $\mathrm{Cd} 3 \mathrm{~d}$, indicating $\mathrm{Cd}(\mathrm{II})$ and $\mathrm{Pb}(\mathrm{II})$ were adsorbed on the biochars.

As shown in Fig. S7, the C 1s spectra of P4 before heavy metal adsorption can be curve-fitted into the forms of $\mathrm{C}-\mathrm{C}(284.7 \mathrm{eV})$, $\mathrm{C}=\mathrm{O}(288.4 \mathrm{eV})$, and $\mathrm{C}-\mathrm{O}(286.2 \mathrm{eV})$. After the adsorption of $\mathrm{Cd}$ (II) or $\mathrm{Pb}(\mathrm{II})$, their $\mathrm{C} 1 \mathrm{~s}$ spectra show that the binding energies of the peaks exhibited a certain degree of shift compared with that of $\mathrm{P} 4$ before $\mathrm{Cd}(\mathrm{II})$ or $\mathrm{Pb}(\mathrm{II})$ adsorption. In particular, the binding energy of $285.5 \mathrm{eV}$, characteristic for $\mathrm{C}-\mathrm{O}$, shows a greater degree of shift. Fig. S7(a) also indicates that the peak area ratio of $\mathrm{C}-\mathrm{O}$ in P4 after adsorption of Cd(II) decreased from $20.18 \%$ to $18.04 \%$ compared with $\mathrm{P} 4$ before adsorption, whereas the peak area of $\mathrm{C}=\mathrm{O}$ increased from $4.4 \%$ to $8.3 \%$. Previous research has indicated that the increase in $\mathrm{C}=\mathrm{O}$ of carboxylic groups should be beneficial to $\mathrm{Cd}^{2+}$ adsorption (Lim et al., 2008). The XPS data suggested the participation of phenolic hydroxyl and carboxylic groups in $\mathrm{Pb}(\mathrm{II})$ and $\mathrm{Cd}(\mathrm{II})$ sorption by biochars, which has been previously demonstrated (Bian et al., 2014).

Similarly, three characteristic peaks were identified for the 01s spectrum in $\mathrm{P} 4$ before and after $\mathrm{Cd}(\mathrm{II})$ or $\mathrm{Pb}(\mathrm{II})$ adsorption (Fig. S7). Compared with the original $\mathrm{P} 4$, the binding energy of $01 \mathrm{~s}$ on the surface of biochar after adsorption increased slightly, indicating that the $\mathrm{O}$ atom was an electron donor during $\mathrm{Cd}(\mathrm{II})$ and $\mathrm{Pb}$ (II) sorption. It should be noted that Oeh (ethers or hydroxyl) in surface P4 (Fig. S7) slightly shifted from 532.3 to $532.1 \mathrm{eV}$. This shift was possibly due to the formation of $\mathrm{Cd}^{2+}$ or $\mathrm{Pb}^{2+}$ complexation in which the oxygen atoms share electrons with $\mathrm{Cd}$, and thus electron densities of oxygen atoms decreases and the binding energy of the oxygen atoms increases.

As shown in Fig. S7, XPS demonstrated that $\mathrm{Pb}(\mathrm{II})$ was present as $\mathrm{Pb}-\mathrm{O}(73.6 \%)$ or as $\mathrm{Pb}^{2+}(26.4 \%)$ and $\mathrm{Cd}(\mathrm{II})$ was present as $\mathrm{Cd}^{2+}$ (69.3\%) or as Cd-O (30.7\%) on the surface of the biochars (Table S6). As shown in Fig. S7(e), two peaks with binding energies of 405.42 and $412.07 \mathrm{eV}$ representing $\mathrm{Cd} 3 \mathrm{~d} 5 / 2$ and $\mathrm{Cd} 3 \mathrm{~d} 3 / 2$, respectively, were observed in the spectra of $\mathrm{P} 4$, indicating $\mathrm{Cd}^{2+}$

Table 2

Contents of oxygen-containing functional groups and total alkaline contents for PP biochar determined by Boehm titration.

\begin{tabular}{|c|c|c|c|c|c|c|c|}
\hline Functional groups & P1 & P2 & P3 & P4 & P5 & P6 & P7 \\
\hline Carboxylic $^{a}$ & $0.15 \pm 0.02$ & $0.18 \pm 0.04$ & $0.13 \pm 0.06$ & $\mathrm{BDL}^{\mathrm{e}}$ & $\mathrm{BDL}$ & $\mathrm{BDL}$ & $\mathrm{BDL}$ \\
\hline Lactonic $^{\mathrm{b}}$ & $0.35 \pm 0.12$ & $0.38 \pm 0.11$ & $0.70 \pm 0.12$ & $0.80 \pm 0.16$ & $0.14 \pm 0.05$ & $\mathrm{BDL}$ & $0.09 \pm 0.03$ \\
\hline Phenolic ${ }^{c}$ & $0.12 \pm 0.05$ & BDL & $0.11 \pm 0.21$ & $0.15 \pm 0.04$ & $0.13 \pm 0.06$ & $0.07 \pm 0.04$ & BDL \\
\hline Total basicity ${ }^{\mathrm{d}}$ & $0.25 \pm 0.09$ & $0.25 \pm 0.10$ & $0.31 \pm 0.12$ & $0.33 \pm 0.11$ & $1.23 \pm 0.12$ & $1.07 \pm 0.21$ & $1.13 \pm 0.18$ \\
\hline
\end{tabular}

a Contents of carboxylic groups $\left(\mathrm{mmol} \cdot \mathrm{g}^{-1}\right)$ calculated as the consumption of $\mathrm{NaHCO}_{3}$.

b Contents of lactonic groups (mmol.g ${ }^{-1}$ ) calculated as the difference in the consumption between $\mathrm{Na}_{2} \mathrm{CO}_{3}$ and $\mathrm{NaHCO}_{3}$.

c Contents of phenolic groups (mmol.g ${ }^{-1}$ ) calculated as the difference in the consumption between $\mathrm{NaOH}$ and $\mathrm{Na}_{2} \mathrm{CO}_{3}$.

d Total basicity (mmol.g ${ }^{-1}$ ) calculated as the consumption of $\mathrm{HCl}$.

e Below detectable level. 
trapped in polyferric flocs. Another pair of less visible peaks in the same sample appearing at 404.57 and $411.20 \mathrm{eV}$ were also ascribed to $\mathrm{Cd} 3 \mathrm{~d} 5 / 2$ and $\mathrm{Cd} 3 \mathrm{~d} 3 / 2$, respectively, caused by $\mathrm{Cd}-\mathrm{O}$ in which $\mathrm{Cd}^{2+}$ is bonded to functional groups such as ether, carboxyl and alcoholic hydroxyl groups on the surface of biochars (Li et al., 2016).

The adsorption of $\mathrm{Pb}^{2+}$ and $\mathrm{Cd}^{2+}$ on $\mathrm{P} 4$ was demonstrated by the SEM-EDX spectra (Fig. S8), and the weight percentages of $\mathrm{Pb}^{2+}$ and $\mathrm{Cd}^{2+}$ in the biochar were $1.92 \%$ and $1.17 \%$, respectively. To confirm the contribution of the chemical precipitation for $\mathrm{Pb}$ (II) and $\mathrm{Cd}(\mathrm{II})$ sorption, the lead loading, and cadmium loading for P1, P3 and P4 were scanned by XRD (Fig. S9). The results were consistent with the trend of ash content increase (Table S5). The biochar samples prepared at higher oxygen atmosphere had a higher mineral ash content, which could enhance precipitation with heavy metals. The XRD spectra of loaded $\mathrm{Pb}^{2+}$ on biochars (Fig. S9) showed several new peaks at specific d-values associated with lead minerals, the precipitation mechanism of lead removal by the PP biochars as shown by Inyang et al. (2012). Carbonate released from the biochars can react with lead in aqueous solution to form stable minerals on biochar. Three types of lead minerals, cerussite $\left(\mathrm{PbCO}_{3}\right)$, hydrocerussite $\left(\mathrm{Pb}_{3}(\mathrm{CO})_{2}(\mathrm{OH})_{2}\right)$, and lead carbon hydrogen oxide $\left(2 \mathrm{PbCO}_{3}{ }^{*} \mathrm{~Pb}(\mathrm{OH})_{2}\right)$, were identified in the post-sorption PP biochar, indicating that lead removal by PP biochar could be controlled by the three precipitation mechanisms. However, lead minerals (for example hydrocerussite or lead carbon hydrogen oxide) on the biochar surface could be dissolved when $\mathrm{pH}$ was relatively low, resulting in a significantly decreased lead adsorption content (Fig. 2). As indicated in Fig. S9(b), only a new peak of $\mathrm{CdCO}_{3}$ (otavite, syn), with the typical $20.84,27.75,33.43,41.32,48.43,57.43$ degree in the $2 \theta$, were observed on post-sorption biochar for $\mathrm{Cd}^{2+}$. The formation may be due to the reactions with $\mathrm{Cd}^{2+}$ and the dissolution components, carbonate, and carbonate minerals such as calcite, have also been found in other biochars (Trakal et al., 2016; Xu et al., 2013). As shown in Fig. S5, Since Whewellite and Calcite cannot be dissolved, the precipitation reactions between heavy metals and insoluble carbonate may have occurred on the surface of the biochar. Biochar samples P3 and P4, which were converted under a $2 \%$ and $4 \%$ oxygen atmosphere respectively, obtained more absorption peaks. This may be because they could release more carbonate to react with the heavy metals in solution.

According to the sorption of $\mathrm{Cd}(\mathrm{II})$ and $\mathrm{Pb}(\mathrm{II})$ on original biochar and demineralized biochars, the contribution of different mechanisms to the $\mathrm{Cd}(\mathrm{II})$ or $\mathrm{Pb}(\mathrm{II})$ on could be calculated by the method

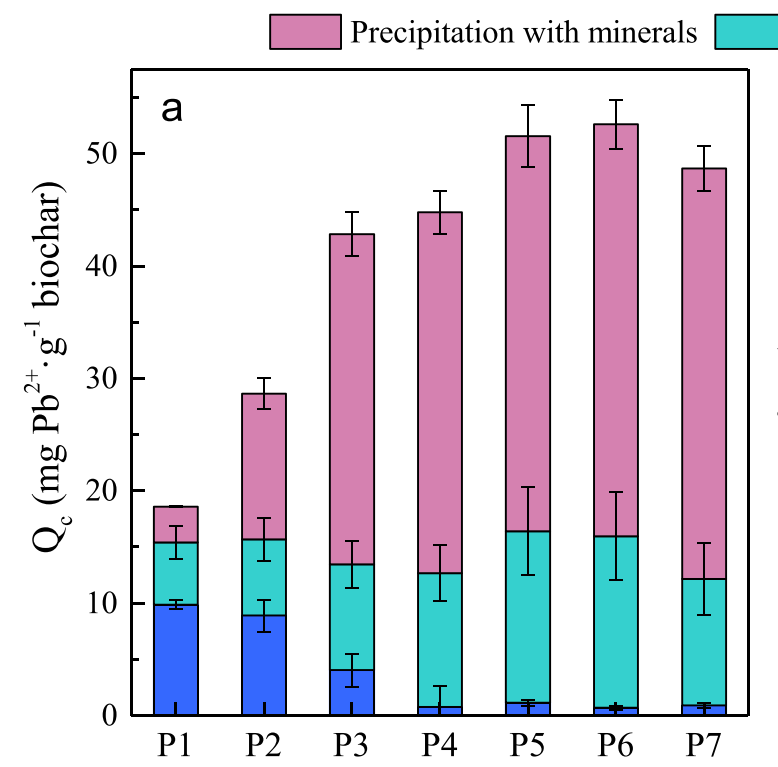

$\mathrm{M}^{2+}-\pi$ interaction $\square$ Functional groups
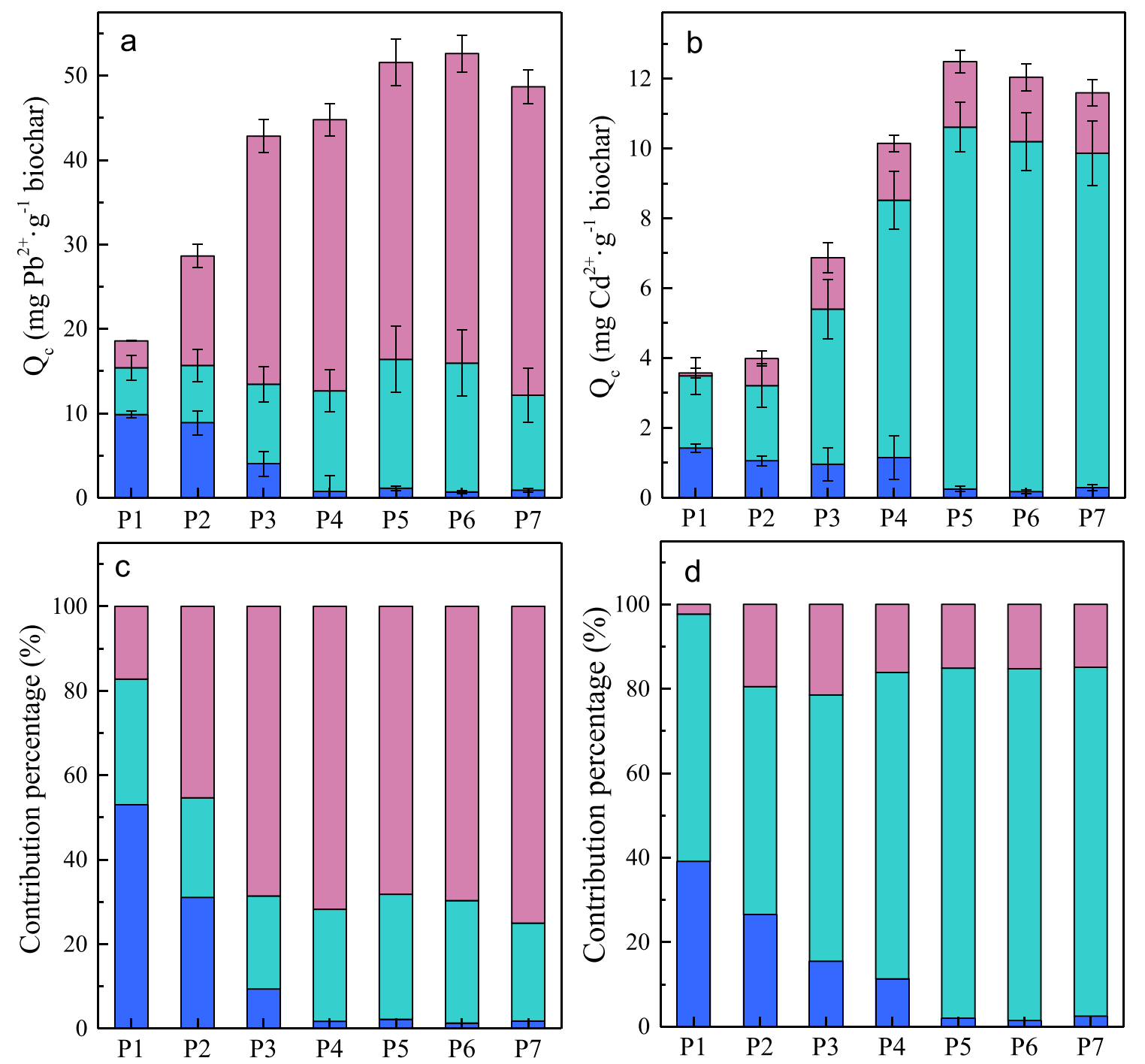

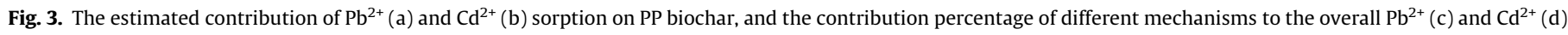
sorption on biochars. 
described in the supporting information. The contribution of Qp, $\mathrm{Qf}$, and $\mathrm{Q} \pi$ to $\mathrm{Qt}$ on biochars is shown in Fig. 3. The contribution for $\mathrm{Pb}^{2+}$ adsorption by PP biochars followed the order $\mathrm{Qp}>\mathrm{Q} \pi>\mathrm{Qf}$, whereas the $\mathrm{Cd}^{2+}$ adsorption followed the order $\mathrm{Q} \pi>\mathrm{Qp}>\mathrm{Qf}$. As shown in Fig. 3a and c, the contribution of Qp significantly increased from $17.2 \%$ to $71.7 \%$ as the oxygen content of the atmosphere increased from $0 \%$ to $4 \%$ at $450{ }^{\circ} \mathrm{C}$. At low pyrolysis temperature, the increased oxygen content of the atmosphere may contribute to the formation of surface minerals, such as carbonate, which could remove $\mathrm{Pb}^{2+}$ in the form of co-precipitation. Use of a trace oxygen atmosphere in pyrolysis process could cause the increase of biochar specific surface area and number of micropores (Table S7), which could provide more adsorption sites for the Pb- $\pi$ complexation. When pyrolysis process trace oxygen increased from $0 \%$ to $4 \%$, the contribution of Qp increased from 3.25 to $32.1 \mathrm{mg} \cdot \mathrm{g}^{-1}$, which is consistent with the mineral precipitation of lead with increasing oxygen content (Fig. S9).

The contribution of $\mathrm{Pb}-\pi$ complexation in $\mathrm{P} 3$ and $\mathrm{P} 6$ reached 18 and $23 \mathrm{mg} \cdot \mathrm{g}^{-1}$, respectively, while the corresponding proportions were $34 \%$ and $43 \%$, respectively. This indicates a good agreement as surface area and porosity significantly increased (Table S7), which may result from aromatization and increased $\pi$ chemical bonds with increased pyrolysis temperature. The contribution of both $\mathrm{Q} \pi$ and $\mathrm{Q} \pi / \mathrm{Qt}$ increased with increasing pyrolysis temperature from 450 to $700{ }^{\circ} \mathrm{C}$, while that of $\mathrm{Qf}$ and $\mathrm{Qf} / \mathrm{Qt}$ showed the reverse trend. For example, the $\mathrm{Qf}$ value of $\mathrm{P} 4$ was $7.06 \mathrm{mg} \mathrm{Pb}^{2+}$ $\mathrm{g}^{-1}$, while the Qf value of P4 was only $3.58 \mathrm{mg} \mathrm{Cd}^{2+} \mathrm{g}^{-1}$ (Fig. 3a). This may be attributed to the amount of oxygen-containing functional groups gradually reducing or disappearing with the temperature increase (Table 2).

The adsorption capacity of $\mathrm{Cd}^{2+}$ by PP biochar was relatively low compared with other biochars (Table S3). The $\mathrm{Q} \pi$ and $\mathrm{Q} \pi / \mathrm{Q}$ t values of the high-temperature biochars $\left(700^{\circ} \mathrm{C}\right)$ were greater than those of the low-temperature biochars $\left(450^{\circ} \mathrm{C}\right)$. For example, the $\mathrm{Q} \pi$ value of P2 was only $2.15 \mathrm{mg} \mathrm{Cd}{ }^{2+} \cdot \mathrm{g}^{-1}$, while the $\mathrm{Q} \pi$ value of P6 was $10.2 \mathrm{mg} \mathrm{Cd}^{2+} \cdot \mathrm{g}^{-1}$, which is approximately 4.7 times greater than that of P2 (Fig. 3b). Similarly, the $\mathrm{Q} \pi / \mathrm{Qt}$ value of P2 was $54.4 \%$, but the Q $\pi$ value of P6 accounted for $83.3 \%$ of its Qt value. For the biochars produced at $450{ }^{\circ} \mathrm{C}$, the contribution of both $\mathrm{Q} \pi$ and $\mathrm{Q} \pi / \mathrm{Qt}$ increased with increasing pyrolysis oxygen atmosphere from $0 \%$ to $4 \%$ (Fig. 3d). Conversely, Qp for the trace oxygen atmosphere biochar (P2, P3 and P4) was roughly equal to the pure nitrogen atmosphere (P1). For example, $\mathrm{Q} \pi$ value of $\mathrm{P} 4$ was $7.36 \mathrm{mg}$ $\mathrm{Cd}^{2+} \cdot \mathrm{g}^{-1}$, accounting for $72.6 \%$ to the $\mathrm{Qt}$ values, while $\mathrm{Q} \pi$ and

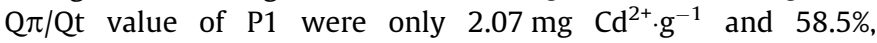
respectively.

Overall, the pyrolysis temperature and atmosphere are crucial for both $\mathrm{Pb}^{2+}$ and $\mathrm{Cd}^{2+}$ sorption capacity of biochars and the contribution of different mechanisms. It could be concluded that $\mathrm{Cd}^{2+}$ attracted to the $\mathrm{C}=\mathrm{C}$ ( $\pi$-electron) bond would predominant mechanism $\mathrm{Cd}^{2+}$ removal, especially for biochar at high pyrolysis temperature. Precipitation between $\mathrm{Pb}^{2+}$ and minerals would also play a key role in $\mathrm{Pb}^{2+}$ removal from water. For $\mathrm{Pb}^{2+}$ adsorption, as the pyrolysis temperature increased, the contribution of Qp increased substantially. The Qp values accounted for $68.2-75.0 \%$ of the Qt values at high pyrolysis temperature, indicating that coprecipitation is the dominant mechanisms of $\mathrm{Pb}^{2+}$ sorption on biochars. At low pyrolysis temperature, the Qp/Qt values of biochar, except for P1, accounted for 45.3-71.7\%, indicating that mineral coprecipitation is the dominant mechanism of $\mathrm{Pb}^{2+}$ sorption. For $\mathrm{Cd}^{2+}$ adsorption, the $\mathrm{Q} \pi$ values accounted for $63.0-74.1 \%$ of the $\mathrm{Qt}$ values, indicating that electrostatic adsorption is the dominant mechanisms of $\mathrm{Cd}^{2+}$ sorption. Therefore, the cadmium adsorption capacity of PP biochar is far less than the lead adsorption capacity, for which mineral ash plays a critical role.

\section{Conclusions}

The PP-derived biochars exhibited different sorption capacities for $\mathrm{Pb}^{2+}$ and $\mathrm{Cd}^{2+}$ under different pyrolysis atmosphere. Importantly, the presence of oxygen in biochar pyrolysis procedure could promote specific surface area and ash content increase at $450^{\circ} \mathrm{C}$. The adsorption capacity of $\mathrm{Pb}^{2+}$ was higher than $\mathrm{Cd}^{2+}$, which is mainly due to mineral precipitation with $\mathrm{Pb}^{2+}$. Precipitation dominated $\mathrm{Pb}^{2+}$ sorption on the biochars and its proportion increased as oxygen content increased. With increasing oxygen content, $\mathrm{Cd}^{2+}-\pi$ interaction was consistently dominant, whereas the contribution of functional groups complexation reduced. This study provides a method for the preparation of cost-effective biochar for metals adsorption.

\section{Acknowledgements}

This research was supported by the Youth Innovation Promotion Association CAS (Wenzhong Tang, 2017059) and the Major Science and Technology Program for Water Pollution Control and Treatment (No. 2012ZX07203-006). We also acknowledge the support received by Wenzhong Tang from the Chinese Scholarship Council (CSC Grant 201604910224).

\section{Appendix A. Supplementary data}

Supplementary data associated with this article can be found, in the online version, at http://dx.doi.org/10.1016/j.biortech.2017.04. 051.

\section{References}

Ahmad, M., Rajapaksha, A.U., Lim, J.E., Zhang, M., Bolan, N., Mohan, D., Vithanage, M., Lee, S.S., Ok, Y.S., 2014. Biochar as a sorbent for contaminant management in soil and water: a review. Chemosphere 99, 19-33.

Angin, D., 2013. Effect of pyrolysis temperature and heating rate on biochar obtained from pyrolysis of safflower seed press cake. Bioresour. Technol. 128, 593-597.

Bell, M.J., Worrall, F., 2011. Charcoal addition to soils in NE England: a carbon sink with environmental co-benefits? Sci. Total Environ. 409 (9), 1704-1714.

Betts, A.R., Chen, N., Hamilton, J.G., Peak, D., 2013. Rates and mechanisms of $\mathrm{Zn}^{2+}$ adsorption on a meat and bonemeal biochar. Environ. Sci. Technol. 47 (24), $14350-14357$

Bian, R., Joseph, S., Cui, L., Pan, G., Li, L., Liu, X., Zhang, A., Rutlidge, H., Wong, S., Chia, C., Marjo, C., Gong, B., Munroe, P., Donne, S., 2014. A three-year experiment confirms continuous immobilization of cadmium and lead in contaminated paddy field with biochar amendment. J. Hazard. Mater. 272, 121-128.

Cao, X.D., Ma, L.N., Gao, B., Harris, W., 2009. Dairy-manure derived biochar effectively sorbs lead and atrazine. Environ. Sci. Technol. 43 (9), 3285-3291.

Chen, T., Zhang, Y., Wang, H., Lu, W., Zhou, Z., Zhang, Y., Ren, L., 2014. Influence of pyrolysis temperature on characteristics and heavy metal adsorptive performance of biochar derived from municipal sewage sludge. Bioresour. Technol. 164, 47-54.

Chen, Z., Xiao, X., Chen, B., Zhu, L., 2015. Quantification of chemical states, dissociation constants and contents of oxygen-containing groups on the surface of biochars produced at different temperatures. Environ. Sci. Technol. 49 (1), 309-317.

Cheung, C., Porter, J., McKay, G., 2000. Sorption kinetics for the removal of copper and zinc from effluents using bone char. Sep. Purif. Technol. 19 (1), 55-64.

Cimò, G., Kucerik, J., Berns, A.E., Schaumann, G.E., Alonzo, G., Conte, P., 2014. Effect of heating time and temperature on the chemical characteristics of biochar from poultry manure. J. Agric. Food Chem. 62 (8), 1912-1918.

Cui, X., Fang, S., Yao, Y., Li, T., Ni, Q., Yang, X., He, Z., 2016. Potential mechanisms of cadmium removal from aqueous solution by Canna indica derived biochar. Sci. Total Environ. 562, 517-525.

Ding, Y., Liu, Y., Liu, S., Li, Z., Tan, X., Huang, X., Zeng, G., Zhou, Y., Zheng, B., Cai, X., 2016. Competitive removal of $\mathrm{Cd}$ (ii) and $\mathrm{Pb}$ (ii) by biochars produced from water hyacinths: performance and mechanism. RSC Adv. 6 (7), 5223-5232.

Dong, X.L., Ma, L.N.Q., Zhu, Y.J., Li, Y.C., Gu, B.H., 2013. Mechanistic investigation of mercury sorption by brazilian pepper biochars of different pyrolytic temperatures based on X-ray photoelectron spectroscopy and flow calorimetry. Environ. Sci. Technol. 47 (21), 12156-12164.

Dong, X., Wang, C., Li, H., Wu, M., Liao, S., Zhang, D., Pan, B., 2014. The sorption of heavy metals on thermally treated sediments with high organic matter content. Bioresour. Technol. 160, 123-128. 
Enders, A., Hanley, K., Whitman, T., Joseph, S., Lehmann, J., 2012. Characterization of biochars to evaluate recalcitrance and agronomic performance. Bioresour. Technol. 114, 644-653.

Fang, Q., Chen, B., Lin, Y., Guan, Y., 2014. Aromatic and hydrophobic surfaces of wood-derived biochar enhance perchlorate adsorption via hydrogen bonding to oxygen-containing organic groups. Environ. Sci. Technol. 48 (1), 279-288.

Goertzen, S.L., Thériault, K.D., Oickle, A.M., Tarasuk, A.C., Andreas, H.A., 2010. Standardization of the Boehm titration. Part I. $\mathrm{CO}_{2}$ expulsion and endpoint determination. Carbon 48 (4), 1252-1261.

Harvey, O.R., Herbert, B.E., Kuo, L.-J., Louchouarn, P., 2012. Generalized twodimensional perturbation correlation infrared spectroscopy reveals mechanisms for the development of surface charge and recalcitrance in plantderived biochars. Environ. Sci. Technol. 46 (19), 10641-10650.

Inyang, M., Dickenson, E., 2015. The potential role of biochar in the removal of organic and microbial contaminants from potable and reuse water: a review. Chemosphere 134, 232-240.

Inyang, M., Gao, B., Yao, Y., Xue, Y., Zimmerman, A.R., Pullammanappallil, P., Cao, X., 2012. Removal of heavy metals from aqueous solution by biochars derived from anaerobically digested biomass. Bioresour. Technol. 110, 50-56.

Jin, L., Bai, R.B., 2002. Mechanisms of lead adsorption on chitosan/PVA hydrogel beads. Langmuir 18 (25), 9765-9770.

Kołodyńska, D., Wnętrzak, R., Leahy, J.J., Hayes, M.H.B., Kwapiński, W., Hubicki, Z., 2012. Kinetic and adsorptive characterization of biochar in metal ions removal. Chem. Eng. J. 197, 295-305.

Li, C., Yi, X., Dang, Z., Yu, H., Zeng, T., Wei, C., Feng, C., 2016. Fate of Fe and Cd upon microbial reduction of Cd-loaded polyferric flocs by Shewanella oneidensis MR1. Chemosphere 144, 2065-2072.

Lim, S.-F., Zheng, Y.-M., Zou, S.-W., Chen, J.P., 2008. Characterization of copper adsorption onto an alginate encapsulated magnetic sorbent by a combined FTIR, XPS, and mathematical modeling study. Environ. Sci. Technol. 42 (7), 25512556.

Liu, W.J., Jiang, H., Yu, H.Q., 2015. Development of biochar-based functional materials: toward a sustainable platform carbon material. Chem. Rev.

Lu, H., Zhang, W., Yang, Y., Huang, X., Wang, S., Qiu, R., 2012. Relative distribution of $\mathrm{Pb}^{2+}$ sorption mechanisms by sludge-derived biochar. Water Res. 46 (3), $854-$ 862.

Luo, L., Xu, C., Chen, Z., Zhang, S., 2015. Properties of biomass-derived biochars: combined effects of operating conditions and biomass types. Bioresour. Technol. 192, 83-89.

Ma, J.C., Dougherty, D.A., 1997. The cation- $\pi$ interaction. Chem. Rev. 97 (5), 13031324.

Mohan, D., Pittman, C.U., Bricka, M., Smith, F., Yancey, B., Mohammad, J., Steele, P.H., Alexandre-Franco, M.F., Gómez-Serrano, V., Gong, H., 2007. Sorption of arsenic, cadmium, and lead by chars produced from fast pyrolysis of wood and bark during bio-oil production. J. Colloid Interface Sci. 310 (1), 57-73.

Mohan, D., Sarswat, A., Ok, Y.S., Pittman Jr., C.U., 2014. Organic and inorganic contaminants removal from water with biochar, a renewable, low cost and sustainable adsorbent-a critical review. Bioresour. Technol. 160, 191-202.

Oickle, A.M., Goertzen, S.L., Hopper, K.R., Abdalla, Y.O., Andreas, H.A., 2010 Standardization of the Boehm titration: Part II. Method of agitation, effect of filtering and dilute titrant. Carbon 48 (12), 3313-3322.

Shokri, A., Abedin, A., Fattahi, A., Kass, S.R., 2012. Effect of hydrogen bonds on pKa values: importance of networking. J. Am. Chem. Soc. 134 (25), 10646-10650.

Tang, J., Mu, B., Zheng, M., Wang, A., 2015. One-step calcination of the spent bleaching earth for the efficient removal of heavy metal ions. ACS Sustainable Chem. Eng. 3 (6), 1125-1135.

Teixidó, M., Pignatello, J.J., Beltrán, J.L., Granados, M., Peccia, J., 2011. Speciation of the ionizable antibiotic sulfamethazine on black carbon (biochar). Environ. Sci. Technol. 45 (23), 10020-10027.

Trakal, L., Veselská, V., Šafařík, I., Vítková, M., Číhalová, S., Komárek, M., 2016. Lead and cadmium sorption mechanisms on magnetically modified biochars. Bioresour. Technol. 203, 318-324.

Wang, Z., Liu, G., Zheng, H., Li, F., Ngo, H.H., Guo, W., Liu, C., Chen, L., Xing, B., 2015 Investigating the mechanisms of biochar's removal of lead from solution. Bioresour. Technol. 177, 308-317.

Xu, X., Cao, X., Zhao, L., 2013. Comparison of rice husk- and dairy manure-derived biochars for simultaneously removing heavy metals from aqueous solutions: role of mineral components in biochars. Chemosphere 92 (8), 955-961.

Xue, Y., Gao, B., Yao, Y., Inyang, M., Zhang, M., Zimmerman, A.R., Ro, K.S., 2012 Hydrogen peroxide modification enhances the ability of biochar (hydrochar) produced from hydrothermal carbonization of peanut hull to remove aqueous heavy metals: batch and column tests. Chem. Eng. J. 200, 673-680.

Yao, S., Zhang, J., Shen, D., Xiao, R., Gu, S., Zhao, M., Liang, J., 2016. Removal of Pb(II) from water by the activated carbon modified by nitric acid under microwave heating. J. Colloid Interface Sci. 463, 118-127.

Zhang W. Mao, S. Chen, H., Huang, L, Qiu, R. 2013. Pb(II) and $\mathrm{Cr}(\mathrm{VI})$ sorption by biochars pyrolyzed from the municipal wastewater sludge under different heating conditions. Bioresour. Technol. 147, 545-552.

Zhang, J., Liu, J., Liu, R., 2015. Effects of pyrolysis temperature and heating time on biochar obtained from the pyrolysis of straw and lignosulfonate. Bioresour. Technol. 176, 288-291.

Zhu, X.D., Liu, Y.C., Zhou, C., Luo, G., Zhang, S.C., Chen, J.M., 2014. A novel porous carbon derived from hydrothermal carbon for efficient adsorption of tetracycline. Carbon 77, 627-636. 